\title{
Familial Renal Glycosuria: a Genetic Reappraisal of Hexose Transport by Kidney and Intestine
}

\author{
Louis J. Elsas and Leon E. Rosenberg \\ From the Division of Medical Genetics, Departments of Medicine ana \\ Pediatrics, Yale University School of Medicine, \\ New Haven, Connecticut 06510
}

\begin{abstract}
A в S T R A C T Renal glucose titration studies were carried out in 10 members of two pedigrees with familial renal glycosuria to test the accepted hypothesis of autosomal dominant inheritance and to investigate the genetic significance of "type A" and "type B" renal glycosuria. In one family, a brother and sister each had a moderately reduced threshold and tubular maximum for glucose (type A), but both of their parents reabsorbed glucose normally. In the second family, two brothers had severe type A renal glycosuria, their mother and one brother had a mild type A defect, and another brother demonstrated a reduced threshold, an exaggerated splay, and a normal tubular maximum, indicative of type $B$ glycosuria.
\end{abstract}

Hexose transport by intestinal mucosa was also investigated in controls and in the three brothers with the most severe renal glycosuria. D-glucose- ${ }^{14} \mathrm{C}$ and $3-O-$ methylglucose $-{ }^{14} \mathrm{C}$ were accumulated by jejunal mucosa from controls by processes which were saturable and concentrative. No differences in hexose transport were observed in the patients with renal glycosuria.

We conclude that familial renal glycosuria can be inherited as an autosomal recessive trait; that mild and severe type A renal glycosuria and type B renal glycosuria can occur in the same pedigree; and that defective reabsorption of glucose by the kidney need not be accompanied by abnormalities in intestinal glucose transport. These findings indicate that glucose transport in the gut and kidney are not mediated by identical mechanisms, and that several different mutations are responsible for the phenotypic variability in familial renal glycosuria.

This study was presented in part at the Annual Meeting of The American Society for Clinical Investigation, May, 1968.

Received for publication 1 April 1969 and in revised form 21 May 1969.

\section{INTRODUCTION}

Familial renal glycosuria results from an inherited defect in the tubular reabsorption of glucose. The condition is diagnosed by finding glucose in the urine when blood glucose concentrations are normal. Although a reabsorptive defect for glucose often occurs in association with generalized proximal tubular dysfunction, we will reserve the term familial renal glycosuria for that condition in which no other abnormality of renal function is demonstrable. Previous investigations of the mode of inheritance of this disorder used oral glucose tolerance tests as the diagnostic technique. Results otbained with this relatively crude technique in a small number of families were interpreted as evidence for autosomal dominant inheritance (1-3). Several observations raised questions about this conclusion. When quantitation of renal glycosuria was attempted, the severity of glycosuria varied considerably within the same sibship (4). The frequency of severe renal glycosuria was less than the frequency of mild renal glycosuria (5-7). Finally, pedigrees were described in which "mild glycosuria" was noted in both parents of a consanguineous mating whose children had "heavy glycosuria" (8).

A more precise means of quantitating renal glucose transport in vivo is available but has not been applied to a genetic analysis of familial renal glycosuria. This technique, known as renal glucose titration, provides an estimate of the minimal threshold (Fmina) and the maximal reabsorptive capacity ( $\mathrm{Tm} \cdot$ ) for glucose (9, 10). This technique has defined two types of abnormal curves in patients with renal glycosuria: type A, characterized by a low threshold and a low Tmo; and type B, characterized by a low threshold, an exaggerated splay. and a normal Tmo (Fig. 1). In the present investigation, glucose titration analyses were performed in 10 members of two pedigrees with renal glycosuria to test the accepted hypothesis of dominant inheritance and to 
determine whether type $A$ and type $B$ renal glycosuria are genetically distinct.

The intestine and the kidney are two organs in man whose functional differentiation for transport is similar. This similarity is correlated with strikingly similar histologic findings in the brush border of the proximal tubular epithelium and the jejunal epithelium (11). Previous investigations have described three inherited disorders of amino acid transport in which renal and intestinal transport defects were associated (12-14). A similar correlation was noted in another inherited defect of glucose transport, the glucose-galactose malabsorption syndrome (15). Because of these previous correlations we investigated intestinal hexose transport in patients with renal glycosuria.

\section{METHODS}

Patients studied. Seven normal volunteers and 10 members of two families with renal glycosuria were admitted to the Clinical Research Center of Yale-New Haven Hospital for study. Each patient was informed in detail of the investigative nature of the study and the procedures to be performed. The diagnosis of renal glycosuria was suspected by finding glycosuria during an otherwise normal glucose tolerance test. Patients were then placed on a calculated diet consisting of $30 \mathrm{cal} / \mathrm{kg}$ and $1 \mathrm{~g}$ of protein per $\mathrm{kg}$. $50 \%$ of the total caloric intake was administered as carbohydrate. The 24-hr urine from patients with renal glycosuria contained excessive glucose when compared with seven normal volunteers maintained on a similar diet (Table I). In patients with renal glycosuria the specificity of their renal tubular defect was confirmed by finding normal clearance of phosphate and uric acid and normal patterns of urinary amino acid excretion by electrophoresis.

Renal glucose titration studies. After an overnight fast, each patient was given $500 \mathrm{ml}$ of water every $30 \mathrm{~min}$ from 7 a.m. to 12 noon to achieve a urinary flow rate of $10-20 \mathrm{ml} /$ min. $2 \mathrm{hr}$ after beginning the water loading, a priming dose of inulin $(50 \mathrm{mg} / \mathrm{kg})$ was administered through an in-

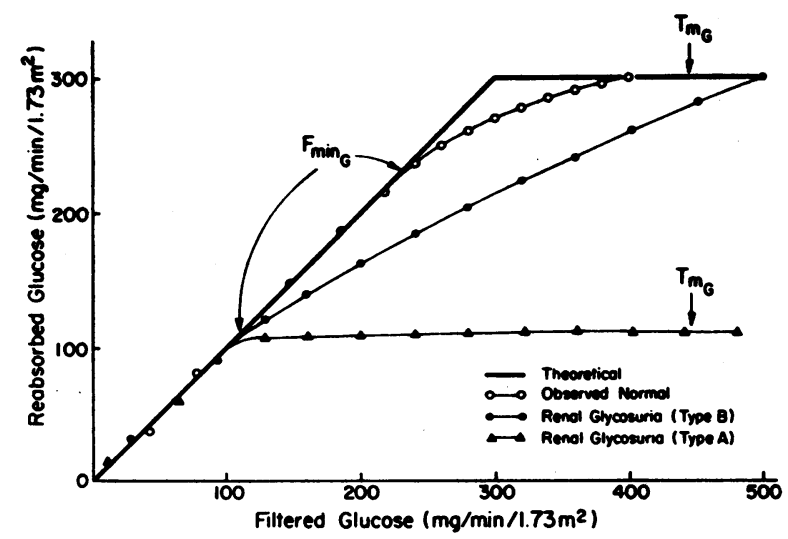

FIgURE 1 Idealized renal glucose titration curves. See Table II for definition of the minimal threshold for filtered glucose $(F \min \theta)$ and the tubular maximum for glucose reabsorption $\left(\mathrm{T} \mathrm{m}_{\mathrm{G}}\right)$.
TABLE I

Normal 24-Hr Urinary Glucose Excretion

\begin{tabular}{ccc}
\hline Subject & BSA* & Urinary glucose \\
\hline & $m^{2}$ & $m g / 24 \mathrm{hr} / 1.73 \mathrm{~m}^{2}$ \\
1 & 2.01 & 133 \\
2 & 1.77 & 132 \\
3 & 1.94 & 192 \\
4 & 1.63 & 284 \\
5 & 1.71 & 178 \\
6 & 1.49 & 246 \\
7 & 1.48 & 316 \\
& & $212 \pm 72 \ddagger$ \\
\hline
\end{tabular}

Seven normal males and females were placed on a calculated diet containing $30 \mathrm{cal} / \mathrm{kg}$ and $1 \mathrm{~g}$ of protein per $\mathrm{kg} .50 \%$ of the total caloric intake was administered as carbohydrate. Urinary glucose was measured by use of glucose oxidase.

* BSA, body surface area.

$\ddagger$ Mean \pm 1 SD.

dwelling venous catheter. A sustaining infusion of inulin (30 $\mathrm{mg} / \mathrm{min}$ ) was then administered with a Harvard constant infusion pump. After a $45 \mathrm{~min}$ equilibration period, the patient emptied his bladder, and two $15 \mathrm{~min}$ renal clearance periods were obtained. At the midpoint of each period, venous blood was obtained for inulin determination; and duplicate arterialized capillary blood samples were analyzed for glucose. After these endogenous clearance periods, increasing blood glucose levels were sustained by increasing the flow rate and concentration of infused glucose. After each change in the infusion rate of glucose, a 15 min equilibration period preceded the collection of duplicate $15-\mathrm{min}$ clearance periods. Thus, $0.5 \mathrm{~g} /$ minute was sustained $15 \mathrm{~min}$ before and during periods 3 and $4,1.0 \mathrm{~g} / \mathrm{min}$ before and during periods 5 and 6 , and $2.5 \mathrm{~g} / \mathrm{min}$ before and during periods 7 and 8. A total of eight clearance periods for inulin and glucose were obtained during each titration study. Arterialized capillary blood samples $(0.1 \mathrm{ml})$ were obtained from the finger tip by heating the hand in warm water $\left(140^{\circ} \mathrm{F}\right)$ for $5 \mathrm{~min}$. Samples were discarded unless a free flow of blood was obtained without undue pressure on the finger tip. All urine samples were obtained without the benefit or risk of an indwelling bladder catheter. Patients emptied their bladders by bearing down at the end of each voiding and signaled the completion of each clearance period.

Inulin ( $10 \%$ solution in sterile water) was purchased from Warner-Chilcott Laboratories, Division of WarnerLambert Pharmaceutical Co., Morris Plains, N. J. Inulin concentration in serum and urine was determined by the method of Walser, Davidson, and Orloff (16). Arterialized capillary blood samples were deproteinized using barium hydroxide and zinc sulfate. D-glucose was determined in blood and urine using glucose oxidase (Glucostat) purchased from Worthington Corporation, Harrison, N. J.

Glucose titration curves were constructed in the following manner (Fig. 1). The filtered glucose load (plotted on the abscissa) was calculated by multiplying the arterialized capillary blood glucose by the inulin clearance. Although the risk of arterial ratheterization was avoided, whole blood glucose rather than plasma glucose concentrations were used in calculating the filtered glucose load. The relationship be- 
TABLE II

Inulin Clearance, Fming, $T m_{G} / C_{i n}, T m_{G}$, and $F_{G} / T m_{G}$ in Seven Normal Volunteers*

\begin{tabular}{|c|c|c|c|c|c|c|c|c|}
\hline $\begin{array}{l}\text { Volunteer } \\
\text { number }\end{array}$ & Age & Sex & BSA & $\begin{array}{l}\text { Inulin } \\
\text { clearance }\end{array}$ & Fmino $_{0}$ & $\mathrm{Tm}_{\mathrm{a}} / \mathrm{C}_{\mathrm{in}}$ & $T m_{G}$ & $F_{a} / T m_{G}$ \\
\hline & $y r$ & & $m^{2}$ & $\mathrm{ml} / \mathrm{min} / 1.73 \mathrm{~m}^{2}$ & $\mathrm{mg} / \mathrm{min} / 1.73 \mathrm{~m}^{2}$ & $m g / m l$ & $\mathrm{mg} / \mathrm{min} / 1.73 \mathrm{~m}^{2}$ & \\
\hline 1 & 40 & $\mathbf{M}$ & 2.08 & 136 & 225 & 2.20 & 300 & 1.41 \\
\hline 2 & 22 & $\mathbf{M}$ & 1.76 & 173 & 220 & 1.84 & 320 & 1.10 \\
\hline 3 & 28 & $\mathbf{M}$ & 2.65 & 124 & 210 & 1.96 & 243 & 1.98 \\
\hline 4 & 19 & $\mathbf{M}$ & 1.86 & 119 & 260 & 2.44 & 290 & 1.49 \\
\hline 5 & 28 & $F$ & 1.64 & 93 & 220 & 2.88 & 270 & 2.23 \\
\hline 6 & 22 & $\mathrm{~F}$ & 1.73 & 112 & 184 & 2.86 & 320 & 1.51 \\
\hline \multirow[t]{2}{*}{7} & 30 & $\mathbf{M}$ & 2.00 & 102 . & 250 & 2.45 & 292 & 1.42 \\
\hline & & & & & $224 \pm 41 \ddagger$ & $2.38 \pm 0.40 \ddagger$ & $291 \pm 27 \ddagger$ & $1.59 \pm 0.38$ \\
\hline
\end{tabular}

* Fmina, minimal threshold for filtered glucose is the filtered glucose load at which significant amounts of glucose ( $>1 \mathrm{mg} / \mathrm{min}$ ) first appears in the urine; $T \mathrm{~m}_{\mathrm{G}}$, tubular maximum for glucose reabsorption indicates the fastest rate of glucose reabsorbed at any filtered glucose load; $\mathrm{F}_{\mathrm{G}}$, maximum filtered glucose loads ranged between 400 and $625 \mathrm{mg} / \mathrm{min}$ per $1.73 \mathrm{~m}^{2}$. Inulin clearance represents the mean of eight 15 min clearance periods.

$\ddagger$ The normal values for $\mathrm{Fmin}_{\mathrm{G}}, \mathrm{Tm}_{\mathrm{G}} / \mathrm{C}_{\mathrm{in}}, \mathrm{F}_{\mathrm{G}} / \mathrm{T} \mathrm{m}_{\mathrm{G}}$, and $\mathrm{T} \mathrm{m}_{\mathrm{G}}$ are expressed as the mean $\pm 1 \mathrm{sD}$.

tween plasma and whole blood glucose under glucose load conditions was not known. If this technique led to an underestimation of the filtered glucose load, and therefore the maximum capacity for glucose reabsorption ( $\left.T m_{6}\right)$, the same underestimation was present in normal controls and in pedigrees affected with renal glycosuria. The reabsorbed glucose (plotted on the ordinate) was calculated by subtracting the observed rate of glucose excretion from the filtered glucose load. All data were normalized to $1.73 \mathrm{~m}^{2}$ of body surface area (BSA). The filtered load at which $1 \mathrm{mg} /$ min of glucose was excreted was defined as the minimal threshold (Fmine). The Tme represented the fastest rate of glucose reabsorption at any filtered glucose load. The Tmo was reached during the last two periods when filtered loads ranged between 400 and $625 \mathrm{mg} / \mathrm{min}$ per $1.73 \mathrm{~m}^{2}$ of BSA. The values for the filtered load and reabsorbed glu- cose were not factored by the Tma to emphasize individual differences in the Fmino, splay from the theoretical curve, and the Tma. A ratio of Tme to clearance of inulin, previously called mean threshold $(10,17)$, was calculated to clarify normal and subnormal Tmo relative to the individual's glomerular filtration rate. The ratio of the highest filtered load $\left(F_{G}\right)$ to $T m_{0}$ was included to document the adequacy of the Tme measurement.

Studies of intestinal hexose transport. The three most severely affected patients from Pedigree Hol (Fig. 3), patients II-4, II-5, and II-7, were selected for peroral intestinal biopsy. Two sets of three normal volunteers were used as controls to study in vitro transport of $3-0$-methylglucose- ${ }^{21} \mathrm{C}$ or D-glucose- ${ }^{14} \mathrm{C}$ by jejunal mucosa. Coagulation studies were obtained before patients were accepted as volunteers. The Quinton $7 \mathrm{~mm}$ hydraulic intestinal biopsy apparatus (18)

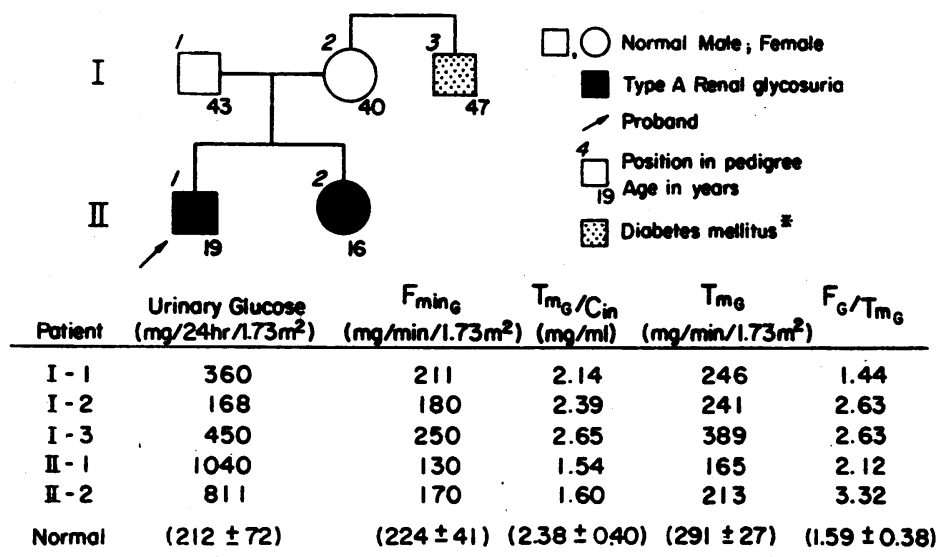

FIgURE 2 Familial renal glycosuria (Pedigree Cov). Normal values are expressed as the mean \pm 1 SD. Roman numerals indicate generation. The diagnosis of diabetes mellitus was made in subject I-3 by oral glucose tolerance test. After $100 \mathrm{~g}$ of D-glucose, blood glucose levels were $131,228,259,253,244$, and $216 \mathrm{mg} / 100 \mathrm{ml}$ at $0, \frac{1}{2}, 1,2,3$, and $4 \mathrm{hr}$, respectively. 
(Quinton Instruments, Seattle, Washington), was used and its tip placed at the ligament of Treitz under fluoroscopic control. $20 \quad 2-3 \mathrm{mg}$ specimens of jejunal mucosa were obtained and kept in Krebs-Ringer bicarbonate buffer for no more than $45 \mathrm{~min}$ before transport studies were initiated. Individual biopsy specimens were placed in $2.0 \mathrm{ml}$ of fresh buffer at $37.5^{\circ} \mathrm{C}, \mathrm{pH} 7.4$, gassed with $95 \% \mathrm{O}_{2}-5 \%$ $\mathrm{CO}_{2}$, and incubated from 5 to $60 \mathrm{~min}$ in a Dubnoff metabolic shaker. Nonradioactive 3-O-methyl-D-glucose was obtained from $\mathrm{K}$ and $\mathrm{K}$ Laboratories Inc., Plainview, $\mathrm{N}$. $\mathrm{Y}$. and D-glucose from Fisher Scientific Company, Pittsburgh, $\mathrm{Pa}$. 3-O-methylglucose $-{ }^{14} \mathrm{C}$ (specific activity $2.7 \mathrm{mc} / \mathrm{mmole}$ ) and D-glucose-UL-14 C (specific activity $6.4 \mathrm{mc} / \mathrm{mmole}$ ) were obtained from New England Nuclear Corp., Boston, Mass. $3-O$-methylglucose ${ }^{24} \mathrm{C}$ was present in $2.0 \mathrm{~mm}$ concentrations and D-glucose-UL- ${ }^{14} \mathrm{C}$ in $1.0 \mathrm{~mm}$ concentrations for the incubation time studies. The remaining biopsy specimens were incubated for $10 \mathrm{~min}$ at hexose concentrations ranging from 0.1 to 40.0 mmoles/liter. At hexose concentrations above 1.0 mmoles/liter equimolar amounts of sodium ion were removed from the incubation medium. At the termination of the incubation, tissue was rinsed, weighed, and homogenized. The tissue homogenate and an aliquot of medium were treated with balanced barium hydroxide and zinc sulfate and centrifuged at $20,000 \mathrm{rpm}$ for $10 \mathrm{~min}$. The clear supernatants were then prepared for liquid scintillation spectrometry, and the distribution ratio for hexose- ${ }^{14} \mathrm{C}$ (counts per minute per milliliter of intracellular fluid divided by counts per minute per milliliter of extracellular fluid) was estimated as previously described (19). $0.5 \mathrm{ml}$ of clear tissue and medium supernatant was analyzed for true glucose using a modified micromethod for glucose oxidase. This method allowed accurate determination of glucose from 2.5 to $25 \mu \mathrm{g} / 0.5 \mathrm{ml}$ sample of tissue extract. In separate experiments tissue extracts, medium, and standards were analyzed for purity by radiochromatography by a descending paper chromatographic system of phenol: water $(160: 40)$ or isopropanol: water $(160: 40)$. Sugars were identified colorimetrically by a diphenylamine : aniline reagent $(20)$.

Kinetic analysis. Since the uptake of glucose into mucosal specimens occurs throngh both physical diffusion and mediated uptake, the intracellular concentration of hexose $\left(A_{c}\right)$ at a given time will be related to both these processes (21). The following equation taken from Akedo and Christensen (22) represents these two forms of uptake:

$$
\frac{\mathrm{dA}}{\mathrm{dt}}=\mathrm{Y}+K_{\mathrm{D}}\left(\mathrm{A}_{\mathrm{t}}-\mathrm{A}_{\mathrm{o}}\right)
$$

Where $\mathrm{Y}$ is the velocity of mediated uptake, $A_{t}$ is the medium concentration, and $K_{\mathrm{D}}$ is the apparent diffusion constant. By integration the above expression becomes:

$$
\frac{A_{0}}{A_{f}}=\frac{Y}{K_{D}}\left(1-\mathrm{e}^{-K_{D} t}\right) \frac{1}{A_{f}}+\left(1-\mathrm{e}^{-K_{D} t}\right) .
$$

At very high concentrations the saturable component will be saturated, and $\mathrm{Y}$ will be constant. Thus in a plot of the distribution ratio $\left(\mathrm{A}_{\mathrm{i}} / \mathrm{A}_{\mathrm{f}}\right)$ vs. the reciprocal of the medium concentration $\left(1 / A_{t}\right)$ a straight line will be obtained at high substrate concentrations with an ordinate intercept of $\left(1-\mathrm{e}^{\left.-K_{\mathrm{D}^{t}}\right)}\right.$. In our experiments a linear relationship was found at 10,20, and $40 \mathrm{~mm}$ hexose, and the $K_{\mathrm{D}}$ was calculated from the observed intercept $\left(1-e^{-K_{D^{t}}}\right)$. The mediated velocity $(Y)$ was calculated by direct substitution into equation 2.

By use of the double-reciprocal plot of Lineweaver and Burk (23), the affinity $\left(K_{m}\right)$ and capacity $\left(\mathrm{V}_{\max }\right)$ were observed directly from the extrapolated abscissal intercept and ordinate intercept, respectively.

\section{RESULTS}

Renal glucose titration studies. The results of renal glucose titration studies in seven normal volunteers are shown in Table II. The mean Fmino was $224 \mathrm{mg} / \mathrm{min}$ per $1.73 \mathrm{~m}^{2}$ of BSA, the mean ratio of Tmo to inulin clearance was $2.38 \mathrm{mg} / \mathrm{ml}$, the mean Tmo was $291 \mathrm{mg} / \mathrm{min}$, and the mean $F_{a} / T_{m}$ was 1.59 . Our values for Tmo are somewhat lower than Smith's published values but similar to those of Reubi and Lambert, all of whom used indwelling arterial catheters and plasma glucose determinations $(9,10,17)$.

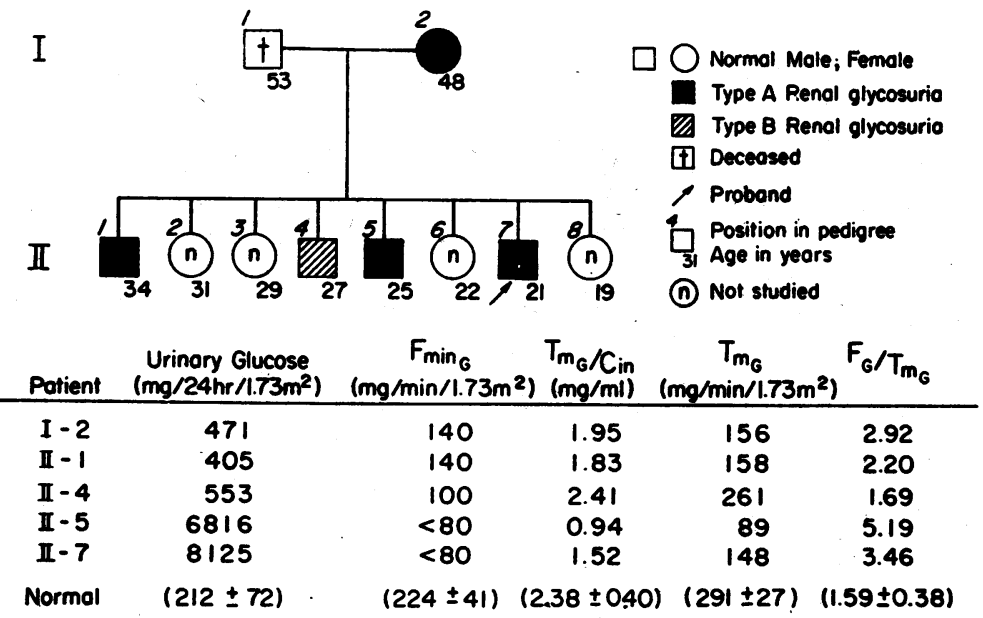

FIgURE 3 Familial renal glycosuria (Pedigree Hol). Fmina $<80$ indicates that significant excretion of glucose occurred below the endogenous filtered glucose load of $80 \mathrm{mg} / \mathrm{min}$ per $1.73 \mathrm{~m}^{2}$. 
The results of titration studies in a Caucasian family (Pedigree Cov) whose 19 yr old son was referred because of intermittent glycosuria are summarized in Fig. 2. The proband, patient II-1, excreted $1040 \mathrm{mg}$ of glucose per $24 \mathrm{hr}$ per $1.73 \mathrm{~m}^{2}$ of BSA. His Fmina, Tma $/ \mathrm{C}_{\mathrm{in}}$, and $T \mathrm{mo}$ were depressed to $130 \mathrm{mg} / \mathrm{min}$ per $1.73 \mathrm{~m}^{2}$ of BSA, $1.54 \mathrm{mg} / \mathrm{ml}$, and $165 \mathrm{mg} /$ minute per $1.73 \mathrm{~m}^{2}$ of BSA, respectively, indicating type A renal glycosuria. His $16 \mathrm{yr}$ old sister also demonstrated type A renal glycosuria with excessive $24 \mathrm{hr}$ urine glucose excretion and depressed $T m_{a} / C_{1 n}$ and $T m_{c}$. All of these values were more than 2 sD below the normal control values. Her Fmina was more than 1 sD but less than 2 sD below normal. In contrast, both parents exhibited normal parameters of renal glucose transport. Their values for urinary glucose, Fmine, $\mathrm{Tm}_{\mathrm{G}} / \mathrm{C}_{\mathbf{l n}}$, and $\mathrm{Tm}$ e fell within 2 SD of normal on two separate studies in each patient. A detailed family history indicated that four other close relatives in four generations had glycosuria. Three of these individuals, a maternal granduncle and grandaunt and a paternal granduncle, were found to have hyperglycemia but were not available for renal glucose titration studies. A maternal uncle, patient I-3, was studied and found to have diabetes mellitus without renal glycosuria (Fig. 2). He exhibited an abnormal oral glucose tolerance test and excreted $450 \mathrm{mg}$ of glucose per $24 \mathrm{hr}$. However, his Fmina, $\mathrm{Tm}_{\mathrm{g}} / \mathrm{C}_{\mathbf{i n}}$, and $\mathrm{Tm}$ o were clearly normal. This finding in patient I-3 clearly dissociated diabetes mellitus from renal glycosuria.

In Pedigree Cov the proband and his sister had intermittent glycosuria. but in a second family, Pedigree $\mathrm{Hol}$
(Fig. 3), the proband, patient II-7, a 21 yr old Negro, had persistent fasting glycosuria. He excreted $8125 \mathrm{mg}$ of glucose in $24 \mathrm{hr}$, a 40 -fold increase over normal. A similar severe renal glycosuria was found in his brother, patient II-5. Both brothers' titration curves were indicative of severe type A renal glycosuria with profoundly depressed Fmina (significant glucose excretion occurred during endogenous glucose loads), and a very low Tmo and $\mathrm{Tm}_{\mathrm{o}} / \mathrm{C}_{\mathrm{in}}$. A less severe form of type A renal glycosuria was found in the mother, patient I-2, and the eldest brother, patient II-1. Both of these individuals excreted excessive amounts of glucose in their $24 \mathrm{hr}$ urine and both had Fmina and Tmo which were depressed more than 2 sD below normal. A third very different type of titration curve was seen in patient II-4. $\mathrm{He}$ excreted significantly more glucose than normal in $24 \mathrm{hr}$. In addition, significant amounts of glucose appeared in his urine at low filtered loads (Fig. 4). His titration curve demonstrated a markedly exaggerated splay from the theoretical normal curve, and most significantly at high filtered glucose loads he reabsorbed glucose well within the normal range. Because errors in measurements of the glomerular filtration rate or of urine or plasma glucose might lead to erroneous values for the Fmina or Tma, a second complete study was performed. An Fmine of $100 \mathrm{mg} /$ minute per $1.73 \mathrm{~m}^{2}$ of BSA was estimated from four filtered loads more than 2 sD below the normal Fmine of $224 \mathrm{mg} / \mathrm{min}$ per $1.73 \mathrm{~m}^{2}$ of BSA. In addition, under the highest glucose load conditions $\left(\mathrm{F}_{\mathrm{o}} / \mathrm{Tm} \mathrm{m}=1.69\right)$, he was able to reabsorb glucose normally during three different clearance

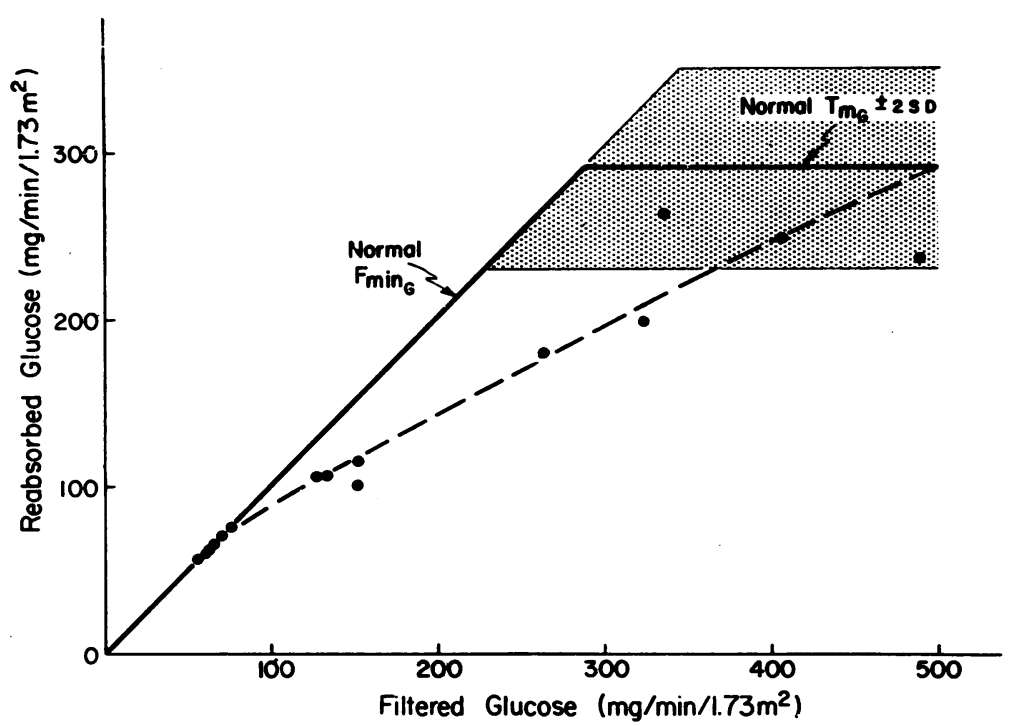

Figure 4 Renal glucose titration curve from patient II-4 (Pedigree Hol). Individual values were obtained from two separate studies of patient with type $B$ renal glycosuria. Shaded area indicates the mean \pm 2 sD of normal values for Tme. The normal Fmino is indicated on the theoretical curve. 
periods. His Tmo was $261 \mathrm{mg} / \mathrm{min}$ per $1.73 \mathrm{~m}^{2}$. This titration curve is characteristic of type $B$ renal glycosuria.

Intestinal transport of 3-O-methylglucose- ${ }^{\text {" }} \mathrm{C}$ and D-glucose ${ }^{14} C$. Intestinal hexose transport was studied in three patients from Pedigree Hol (patients II-4, II-5, and II-7) who exhibited the most severe renal defect for glucose transport. Several kinds of studies of 3-O-methylglucose- ${ }^{14} \mathrm{C}$ uptake by jejunal mucosa failed to detect an intestinal transport defect. As indicated in Fig. 5, normal controls concentrated this glucose analogue to intracellular concentrations eight times that in the incubation medium. More importantly, the three patients accumulated this hexose to distribution ratios indistinguishable from normal throughout the $60 \mathrm{~min}$ time course. In addition, a kinetic analysis of 3-O-methylglucose- ${ }^{14} \mathrm{C}$ transport over a 400 -fold substrate concentration range failed to differentiate patients with renal glycosuria from normal controls (Fig. 6). Uptake of this hexose by jejunal mucosa demonstrated saturability and could be plotted in the double-reciprocal manner of Lineweaver and Burk (23). An apparent $K_{m}$ of 7.7 mmoles/liter and a $V_{\max }$ of 25 mmoles/liter per $10 \mathrm{~min}$ was obtained. No change in the affinity or capacity of the jejunal transport system for 3-O-methylglucose was observed in patients with renal glycosuria.

Although 3-O-methylglucose shares at least one carrier mechanism with $\mathrm{D}$-glucose $(24,25)$, the inherited glucose transport defect in renal glycosuria may not involve the same intestinal carrier mechanism. Therefore, an investigation of D-glucose uptake was undertaken in normal controls and in patient II-7 from Pedigree Hol. No abnormality for D-glucose uptake could be discerned. The results of a single incubation time study over a $60 \mathrm{~min}$ period is shown in Table III. Uptake by jejunal mucosa from the patient and control was similar at each time point. D-glucose was accumulated in the tissues to concentrations greater than 20 times the medium. That $\mathrm{D}$-glucose $-{ }^{11} \mathrm{C}$ was present in tissue and media as true D-glucose was confirmed by radiochromatography and by simultaneous enzymatic determination of glucose. Thus, glucose transport was rate limiting, and $\mathrm{D}$-glucose- ${ }^{14} C$ could be used for the kinetic analysis demonstrated in Fig. 7. An apparent $K_{m}$ of $4.2 \mathrm{mmoles} /$ liter and $V_{\max }$ of $55.5 \mathrm{mmoles} /$ liter per $10 \mathrm{~min}$ in normal controls indicated the higher affinity and capacity of jejunal mucosa for D-glucose transport than for 3-O-methylglucose transport. Again, no differences in these parameters were detected in the patient

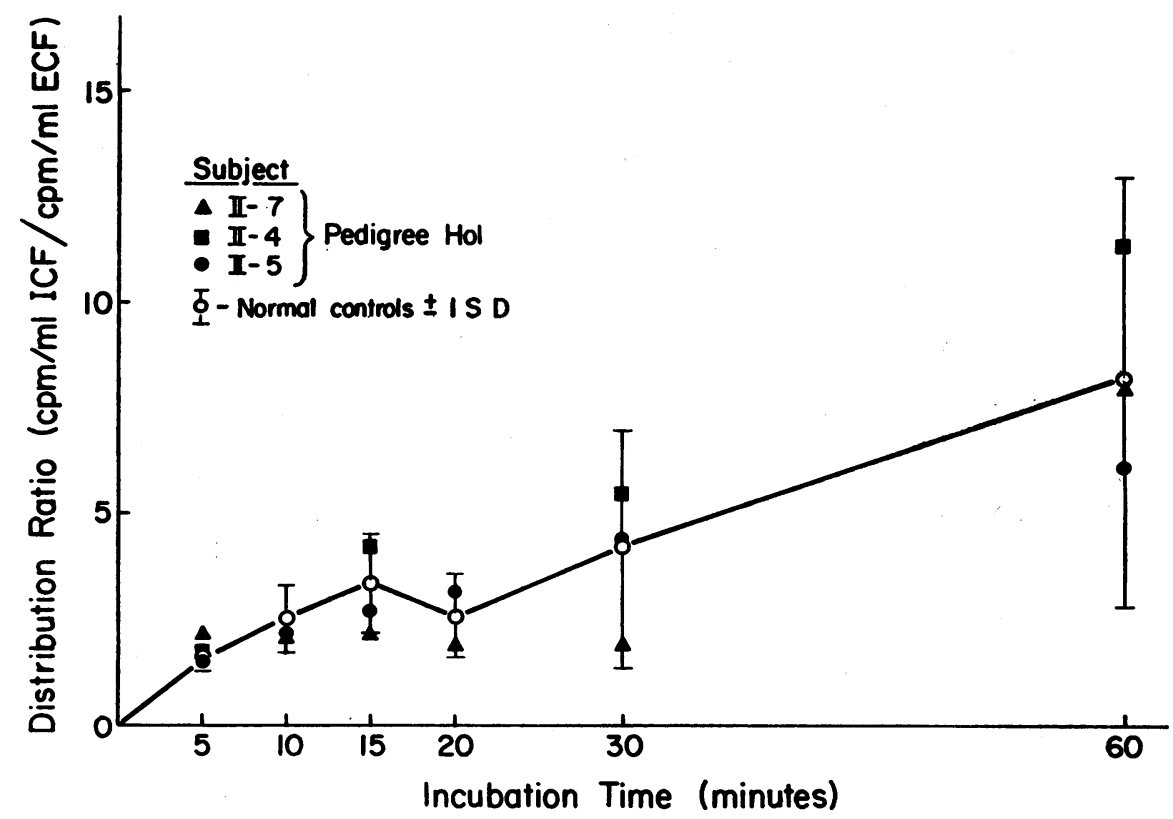

Figure 5 Jejunal transport of 3-O-methylglucose- ${ }^{14} \mathrm{C} .202-4 \mathrm{mg}$ specimens of jejunal mucosa were obtained using a peroral hydraulic biopsy tube. A single biopsy specimen was placed in $2.0 \mathrm{ml}$ of Krebs-Ringer bicarbonate buffer, $\mathrm{pH} 7.4$, at $37.5^{\circ} \mathrm{C}$, gassed with $95 \% \mathrm{O}_{2}-5 \% \mathrm{CO}_{2}$, and incubated with $3-O$-methylglucose $-{ }^{14} \mathrm{C}(2.0 \mathrm{mmoles} / \mathrm{liter})$ for the times indicated. Results in normal controls (three) are expressed as the mean of six observations bracketed by 1 SD. Results from three patients with renal glycosuria are expressed as their individual values at each time point. ICF, intracellular fluid; ECF, extracellular fluid. 
with renal glycosuria. To our knowledge these studies represent the first published kinetic analyses of in vitro glucose transport by human jejunal mucosa. The values for $K_{m}$ and $\mathrm{V}_{\max }$ were similar to those obtained by Crane from hamster jejunum (25).

\section{DISCUSSION}

Renal tubular reabsorption of glucose requires an active transport system which presumably involves a stereospecific membrane-carrier mechanism. This catalytic reaction requires energy and is competitively inhibited by phlorhizin (26). The in vivo saturation of renal tubular glucose reabsorption demonstrated by glucose titration techniques may be considered analogous to in vitro enzyme kinetics. As the substrate concentration (filtered glucose load) is increased, the velocity of the reaction (tubular reabsorption of glucose) is increased until a maximum velocity ( $\mathrm{Tm} \theta$ ) is reached. Thereafter, further increases in substrate concentration are not accompanied by increases in the velocity, because the capacity of the system has been reached. The initial step

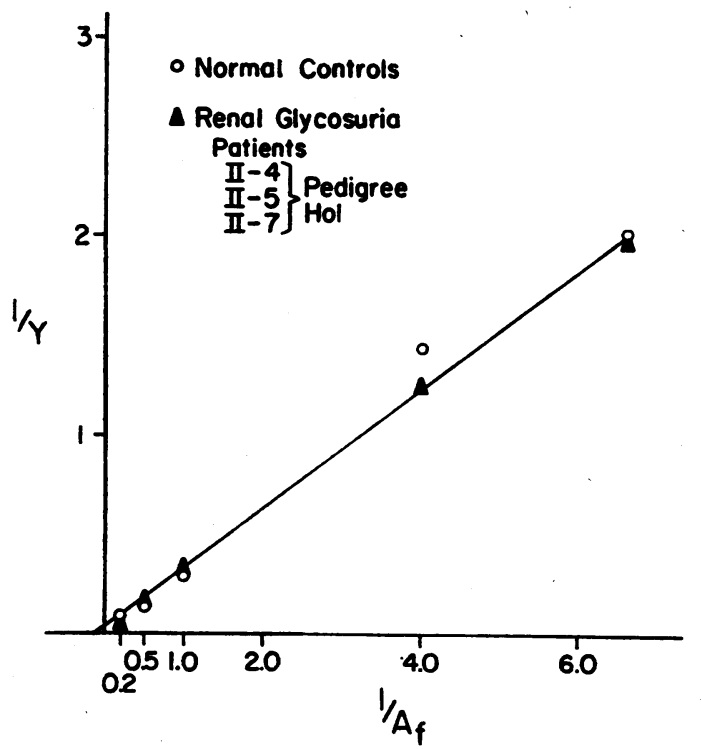

Figure 6 Kinetic analysis of 3-O-methylglucose- ${ }^{10} \mathrm{C}$ transport by jejunal mucosa from normal controls (three) and patients with renal glycosuria (three). Biopsy specimens were incubated for $10 \mathrm{~min}$ with $3-0$-methylglucose- ${ }^{-14} \mathrm{C}$ over a 400-fold concentration range. For calculation of mediated velocity $(Y)$, see Methods section. The reciprocal of the mediated velocity $(1 / Y)$ was plotted against the reciprocal of the medium concentration $\left(1 / A_{f}\right)$. Individual points represent the mean of six observations in three controls and in three patients with renal glycosuria. The affinity $\left(K_{m}\right)$ and capacity ( $V_{\text {mas }}$ ) were calculated from the extrapolated abscissal intercept and ordinate intercept, respectively. A $K_{m}$ of 7.7 mmoles/liter and a $V_{\max }$ of 25 mmoles/liter per 10 min were observed for both normal controls and patients with renal glycosuria.
TABLE III

D-Glucose Transport by Jejunal Mucosa in Controls and Patient II-7 (Pedigree Hol)

\begin{tabular}{ccc}
\hline & \multicolumn{2}{c}{$\begin{array}{c}\text { Distribution ratio for } \\
\text { D-Glucose-14C }\end{array}$} \\
\cline { 2 - 3 } Duration of & \multicolumn{2}{c}{ Control } \\
\hline $\min$ & & \\
5 & 3.5 & $7.1(6.5)^{*}$ \\
10 & 11.7 & $15.3(16.7)$ \\
15 & 14.8 & 13.5 \\
30 & 15.1 & $25.7(25.3)$ \\
60 & 23.2 & $24.9(27.1)$ \\
\hline
\end{tabular}

Jejunal biopsy specimens were incubated in $\mathrm{D}$-glucose- ${ }^{14} \mathrm{C}$ (1.0 mmoles/liter) under conditions indicated in Fig. 5. Results in a single control and the patient are expressed as the average of duplicate observations.

* Numbers in parenthesis denotes the distribution ratios for true D-glucose obtained spectrophotometrically by use of glucose oxidase.

in this transfer process requires reversible complexing of glucose (G) with a carrier substance (C) to form a glucose-carrier complex (GC). A symbolic expression for this equilibrium can be written: $[\mathrm{G}]+[\mathrm{C}] \rightleftharpoons[\mathrm{GC}]$. This initial step can also be written as an equation of mass action :

$$
\frac{[\mathrm{G}][\mathrm{C}]}{[\mathrm{GC}]}=K \text {. }
$$

From this expression one can readily see that there will always be some unbound glucose $(G)$ and unbound carrier (C). If the dissociation constant $(K)$ is small, a smaller amount of glucose will be unbound and appear in the urine than if $K$ is large. When $K$ is large, the affinity of the carrier for glucose is low, and a larger amount of glucose will appear in the urine. The minimal threshold obtained by in vivo titration techniques is, thus, analogous to this dissociation constant. Using these principles of enzyme kinetics, Woolf, Goodwin, and Phelps (27) derived an expression and plotted curves for glucose reabsorption in a model nephron. The curves resembled experimentally observed normal renal glucose titration curves, when a normal number of carrier units with normal affinity for glucose were postulated. When the expression representing carrier units was reduced, a curve resembling type $A$ renal glycosuria was observed. When the expression representing affinity was altered without changing the expression for the number of carrier sites, a curve resembling type $\mathrm{B}$ renal glycosuria was observed. Thus, it is possible to account for both types of renal glycosuria without postulating different populations of nephrons or glomerulotubular imbalance. 
The trait for familial renal glycosuria is classically defined as an autosomal dominant one (1-3). This concept was based on $\mathrm{Hjärne's} \mathrm{study} \mathrm{in} \mathrm{three} \mathrm{generations}$ of a single family. 24 individuals demonstrated glycosuria without hyperglycemia $2 \mathrm{hr}$ after oral glucose loading. When this nonquantitative method of detection was used, direct parent-to-offspring transmission of the trait was seen, males and females were equally affected; where neither parent was affected, no offspring were affected. This means of detection, however, did not differentiate mild and severe glycosuria. Thus it is probable that the affected members of this and subsequent pedigrees demonstrating a dominant pattern of inheritance represent heterozygotes and homozygotes for different glucose transport mutations. In 1964, Khachadurian and Khachadurian described three pedigrees, two of which contained consanguineous matings. By quantitating 24-hr urinary glucose excretion these authors found that the parents demonstrated "mild" glycosuria, and six offspring demonstrated "heavy" glycosuria (8). These findings suggested that the offspring were homozygous for the mutant gene, and that the parents were heterozygotes.

Since renal titration analysis provides quantitative information about tubular absorption of glucose not obtainable by any other in vivo approach, we presumed that the use of this technique in a pedigree analysis of familial renal glycosuria should clarify the genetics of this disorder. The results of our investigation in two pedigrees using such titration techniques are sum-

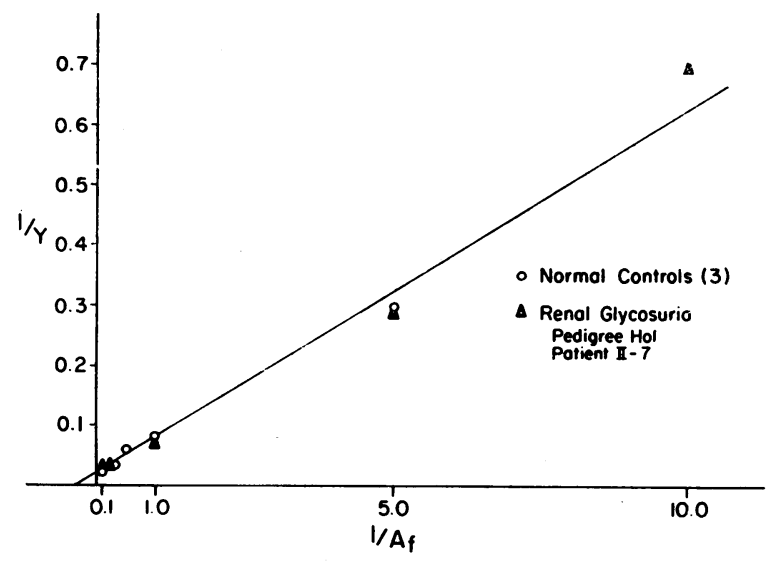

Figure 7 Kinetic analysis of D-glucose $-{ }^{14} \mathrm{C}$ uptake by jejunal mucosa in normal controls and in patient II-7 (Pedigree Hol). Biopsy specimens were incubated for 10 min in D-glucose $-{ }^{14} \mathrm{C}$. Incubation conditions and kinetic analysis are described in Fig. 6. Data obtained in normal controls represents the mean of six observations in three volunteers. The data from the patient represents the mean of duplicate observations at each medium concentration. The apparent $K_{m}$ was $4.2 \mathrm{mmoles} / \mathrm{liter}$, and the $\mathrm{V}_{\mathrm{mar}}$ was $55.5 \mathrm{mmoles} / \mathrm{liter}$ per $10 \mathrm{~min}$.

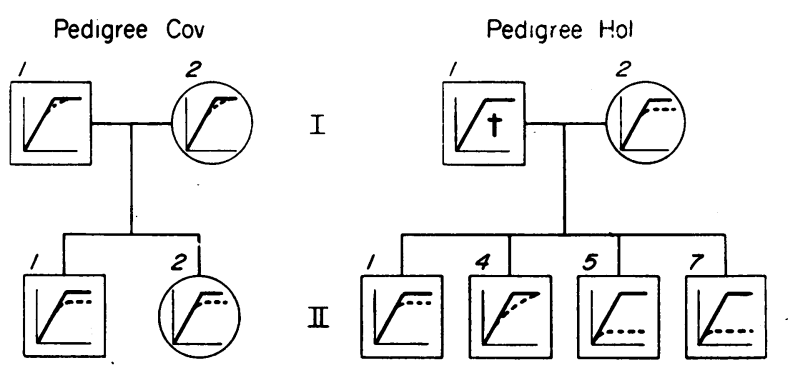

FigURE 8 Familial renal glycosuria: symbolic renal glucose titration curves observed in Pedigrees Cov and Hol. Roman numerals indicate the generation and superscript numerals the position in the pedigree. The heavy black line indicates the theoretical curve, the broken line the observed deviation from the theoretical curve.

marized in Fig. 8. It seems likely that the abnormalities are genetically determined since seven out of 10 members in two pedigrees demonstrate isolated tubular transport defects for glucose. In Pedigree Cov, a brother and a sister have mild type A renal glycosuria, and both parents are normal. Thus in Pedigree Cov. type A renal glycosuria is inherited as a recessive trait. In the second family, Pedigree Hol, two brothers have severe type A glycosuria, the mother and one brother have mild type A glycosuria, and one brother has type B glycosuria. Thus, in Pedigree Hol, three types of titration curves were noted in a single family. Perhaps they represent variable expressions of a dominant mutation. Although we cannot exclude this possibility in Pedigree $\mathrm{Hol}$, this thesis would require both qualitative and quantitative variability in the results of renal glucose titration. An alternate hypothesis suggests that type $\mathrm{A}$ and type $B$ renal glycosuria reflect different mutations, the mutant A gene resulting in a reduced capacity, the mutant $B$ gene resulting in a reduced affinity for glucosereabsorption. This theory implies that the mother, patient I-2, and brother, II- 1 , are heterozygous for the mutant $\mathrm{A}$ gene resulting in mild type A renal glycosuria; that the deceased father and brother II- 4 are heterozygous for the mutant B gene resulting in type B renal glycosuria; and that the proband, subject II-7, and brother, II-5 are doubly heterozygous for both mutant genes which are expressed as severe type A renal glycosuria. Since the father is deceased, future studies in the offspring of generation II will be needed to test this hypothesis.

In three other inherited diseases of renal transport, defects in the kidney are associated with intestinal transport defects (12-14). In hopes of clarifying the mode of inheritance in Pedigree Hol, hexose transport by intestine was studied in the two brothers with severe type $\mathrm{A}$ and one brother with type $\mathrm{B}$ renal glycosuria. Since 3-O-methylglucose shares an intestinal transport 
site with D-glucose $(24,25)$, the transport of this nonmetabolized analogue was investigated first. Uptake of this hexose was no different in the patients than in controls. The biopsy specimens from both groups demonstrated saturation kinetics with similar capacity and affinity for 3-O-methylglucose transport. Since the defect for glucose transport might affect a carrier mechanism which is not shared with 3-O-methylglucose, the transport of true glucose was also investigated in intestinal mucosa from the most severely affected patient with type A renal glycosuria. No impairment in uptake or saturation kinetics was found in this patient. Thus, in this family with renal glycosuria, the kidney and intestine do not share a defective hexose transport system.

It seems likely that the phenotypic variation in patients with familial renal glycosuria reflects several different mutations. In some families (Pedigree Cov) the presumed carriers are not detectable by glucose titration techniques as they are in others (Pedigree $\mathrm{Hol})$. In some affected individuals the capacity for renal glucose transport is impaired, whereas in others only the threshold is lowered. In some families (Pedigree $\mathrm{Hol}$ ) a severe defect in renal glucose transport is not accompanied by a defective intestinal glucose transport. However, in another inherited disease of glucose transport, the glucose-galactose malabsorption syndrome (15), a specific renal glucose transport defect is accompanied by a severe intestinal defect. These observations indicate the complexity of familial renal glycosuria and the need for further investigation using similar techniques for evaluating inherited variations in transmembrane transport.

\section{ACKNOWLEDGMENTS}

We are indebted to Dr. Edward Etkind and Dr. Marvin Lillian for referring the affected probands and for their support in the family studies. We also thank Mrs. Ann Altman, Miss Anne-Charlotte Lilljeqvist, and Mrs. Isidora Albrecht for their invaluable technical assistance, the entire nursing staff of the Clinical Research Unit for their devoted patient care, and the section of Gastroenterology for allowing us to borrow their biopsy equipment.

This work was supported by a Clinical Research Center Grant from the National Institutes of Health (FR-00125). Dr. Elsas was supported by a special Postdoctoral Fellowship from the U. S. Public Health Service (2-F3-AM-35,615). Dr. Rosenberg was supported by research grants from the U. S. Public Health Service (AM 09527), the John A. Hartford Foundation. and by a Research Career Development Award (AM 28087) from the National Institute of Arthritis and Metabolic Diseases.

\section{REFERENCES}

1. Hjärne, V. 1927. A study of orthoglycaemic glycosuria with particular reference to its hereditability. Acta. Med. Scand. $67: 422$.
2. Houston, J. C., and W. H. H. Merivale. 1949. Renal glycosuria in a family. Guy's Hosp. Rep. 98: 233.

3. Brown, M. S., and R. Poleshuck. 1935. Familial renal glycosuria. J. Lab. Clin. Med. 20: 605.

4. Froesch, E. R., A. I. Winegrad, and A. E. Renold. 1957. Die tubulare Nierenfunktion bein verschiedenen Formen des renalen Diabetes mellitus. Helvet. Med. Acta. 24: 548.

5. Marble, A. 1952. Non-diabetic mellituria. In The Treatment of Diabetes Mellitus. E. P. Joslin, H. F. Root, P. White, and A. Marble, editors. Lea \& Febiger, Philadelphia. 699.

6. Lawrence, R. D. 1947. Symptomless glycosurias: differentiation by sugar tolerance tests. Med. Clin. N. Amer. 31: 289.

7. Harkness, J. 1962. Prevalence of glycosuria and diabetes mellitus. Brit. Med. J. 1: 1503.

8. Khachadurian, A. K., and L. A. Khachadurian. 1964. The inheritance of renal glyosuria. Amer. J. Hum. Genet. 16: 189.

9. Smith, H. W., W. Goldring, H. Chasis, H. A. Ranges, and S. E. Bradley. 1943. The William Henry Welch Lectures. II. The application of saturation methods to the study of glomerular and tubular function in the human kidney. J. Mt. Sinai Hosp. 10: 59.

10. Reubi, F. C. 1954. Glucose titration in renal glycosuria. In Ciba Foundation Symposium on the Kidney. A. A. G. Lewis and G. E. W. Wolstenholme, editors. Little, Brown and Company, Boston. 96.

11. Rhodin, J. 1958. Electron microscopy of the kidney. Amer. J. Med. 24: 661.

12. Rosenberg, L. E., S. Downing, J. L. Durant, and S. Segal. 1966. Cystinuria: biochemical evidence for three genetically distinct diseases. J. Clin. Invest. 45: 365 .

13. Jepson, J. B. 1966. Hartnup disease. In The Metabolic Basis of Inherited Disease. J. B. Stanbury, J. B. Wyngaarden, and D. J. Fredrickson, editors. McGraw-Hill Book Company, New York. 2nd edition. 1283.

14. Morikawa, T., K. Tada, T. Ando, T. Yoshida, Y. Yokoyama, and T. Arakawa. 1966. Prolinuria: defect in intestinal absorption of imino acids and glycine. Tohoku J. Exp. Med. 90: 105.

15. Elsas, L. J., R. E. Hillman, J. H. Patterson, and L. E. Rosenberg. 1969. Renal and instestinal hexose transport in the glucose-galactose malabsorption syndrome. Clin. Res. 17: 28. (Abstr.)

16. Walser, M., D. G. Davidson, and J. Orloff. 1955. Renal clearance of alkalistable inulin. J. Clin. Invest. 34: 1520 .

17. Lambert, P. P. 1954. A study of the mechanism by which toxic tubular damage changes the renal threshold for glucose. In Ciba Foundation Symposium on the Kidney. A. A. G. Lewis and G. E. W. Wolstenholme, editors. Little, Brown and Company, Boston. 79.

18. Flick, A. L., W. E. Quinton, and C. E. Rubin. 1961. A peroral hydraulic biopsy tube for multiple sampling at any level of the gastrointestinal tract. Gastroenterology.. $40: 120$.

19. Rosenberg, L. E., A. Blair, and S. Segal. 1961. Transport of amino acids by slires of rat-kidney cortex. Biochim. Biophys. Acta. 54: 479.

20. Smith, I. 1960. Sugars. In Chromatographic and Electrophoretic Techniques. Pitman Press, Bath. 2nd edition. 246.

21. Crane, R. K. 1960 . Intestinal absorption of sugars. Physiol. Rev. 40: 789. 
22. Akedo, H., and H. N. Christensen. 1962. Nature of insulin action on amino acid uptake by the isolated diaphragm. J. Biol. Chem. 237: 118.

23. Lineweaver, H., and D. J. Burk. 1934. Determination of enzyme dissociation constants. Amer. Chem. Soc. 56: 658.

24. Csaky, T. Z. 1958. Active intestinal transport of 3-Omethylglucose. Abstracts from Proceedings of the 4th International Congress of Biochemistry. 15: 80 .
25. Crane, R. K. 1960 . Studies on the mechanism of the intestinal absorption of sugars. III. Mutual inhibition in vitro between some actively transported sugars. Biochim. Biophys. Acta. 45: 477.

26. Taggart, J. V. 1958. Mechanisms of renal tubular transport. Amer. J. Med. $24: 774$.

27. Woolf, L. I., B. L. Goodwin, and C. E. Phelps. 1966. $\mathrm{T}_{\mathrm{m}}$-limited renal tubular reabsorption and the genetics of renal glucosuria. J. Theor. Biol. 11: 10. 